\title{
Radiografía demográfica y socioeconómica de un espacio urbano. Segovia 1860-1905
}

\author{
Demographic and socioeconomic radiography of the urban space. \\ Segovia 1860-1905 \\ Dr. Rubén DE LA FUENTE NÚÑEZ \\ Universidad Internacional de la Rioja \\ ruben.delafuente@unir.net \\ https://orcid.org/0000-0003-2833-6246
}

Resumen: El objetivo de este artículo es estudiar las características de la población de Segovia desde 1860 a 1905, atendiendo a su origen, evolución, comportamiento, estructuras familiares, su distribución en la capital y la segregación horizontal y vertical del espacio urbano. Para ello, y basándonos en el estudio exhaustivo de los padrones municipales de 1860, 1881 y 1905, arbitrios sobre inquilinatos, expedientes administrativos municipales, matrículas industriales, fuentes contemporáneas y prensa local, entre otras, se ha realizado una radiografía demográfica, socioeconómica y espacial de la población que además pueda servir de comparación con otros núcleos nacionales.

Abstract: The aim of this article it is to study the population of Segovia from 1860 to 1905, taking into account their origin, evolution, family structures, their distribution in the capital and the horizontal and vertical segregation of urban space. For this, and based on the exhaustive study of the municipal registers of 1860, 1881 and 1905, taxes on tenancies, municipal administrative files, industrial license plates, contemporary sources and local press, among others, a demographic, socioeconomic and spacial radiography of the population is carried out that can also serve as a comparison with other national centers.

Palabras Clave: Segovia 1860-1905. Demografía. Segregación horizontal y vertical. Espacio urbano. Asentamiento poblacional.

Keywords: Segovia 1860-1905. Demography. Horizontal and vertical segregation. Urban space. Population settlement 
Sumario:

\section{Introducción.}

II. La población de Segovia 1860-1905.

2.1. Origen de la población.

III. Distribución espacial de la población segoviana.

IV. Intramuros.

4.1. Parroquia de La Catedral.

4.2. Parroquias de La Trinidad y San Nicolás.

4.3. Parroquia de San Miguel.

4.4. Parroquia de San Andrés.

4.5. Parroquia de San Martín.

4.6. Parroquia de San Esteban.

4.7. Parroquias de San Sebastián, San Román, San Juan y San Facundo.

V. Arrabales Unidos.

5.1. Parroquia de Santa Columba.

5.2. Parroquia de San Clemente.

5.3. Parroquia de San Millán.

5.4. Parroquia de Santa Eulalia.

5.5. Parroquia de Santo Tomás.

5.6. Parroquia del Salvador.

5.7. Parroquia de San Justo.

VI. Arrabales separados.

6.1. Parroquia de San Lorenzo.

6.2. Parroquia de San Marcos.

VII. Conclusiones.

VIII. Bibliografía.

Recibido: septiembre 2021.

Aceptado: noviembre 2021. 


\section{INTRODUCCIÓN}

El crecimiento de los estudios demográficos en España ha tenido un gran éxito gracias a las múltiples investigaciones, prismas metodológicos y diversidad de objetivos desarrollados en los últimos años. La reforma de este campo historiográfico, iniciado en los años setenta por Laslett, Hajnal o Wrigley, se extendió rápidamente por todo el continente. En el caso español, la influencia de estos historiadores se empezó a notar claramente una década después, en la que la disciplina de la demografía histórica ocupó un lugar importante en la historiografía española. Los principales avances que marcaron la distinción metodológica y conceptual fueron las obras pioneras de Vicente Pérez Moreda o David Sven Reher y la fundación de la Asociación de Demografía Histórica (ADEH) ${ }^{1}$.

El análisis de la estructura y la transición demográfica española ha dado paso a nuevos e infinitos esfuerzos por estudiar espacios específicos. En ellos, se persigue entender con mayor precisión la importancia de las diferentes etapas y prácticas migratorias en la composición de las sociedades modernas, tanto urbanas como rurales, estudiar las distintas formas y estrategias vitales de las familias ${ }^{2}$ y como no, comparar la evolución de los mercados de trabajo con los aspectos anteriores. Todo ello no es más que la utilización de otros puntos de acercamiento al estudio de las transformaciones y pervivencias sociales que afectaron a la población española ${ }^{3}$.

\footnotetext{
${ }^{1}$ Destacan de forma especial las obras de PÉREZ MOREDA, V., Las crisis de la mortalidad en la España interior, siglos XVI-XX, Madrid, siglo XXI, 1980. PÉREZ MOREDA, V. y REHER, D. S., Demografía histórica en España, Madrid, El Arquero, 1988. REHER, D. S., Familia, población y sociedad en la provincia de Cuenca, 1700-1970, Madrid, CIS-Siglo XXI, 1988.

${ }^{2}$ Estas estrategias familiares es un término usado por los antropólogos para describir los mecanismos de comportamiento de grupos familiares dentro de su contexto económico y social. Para los historiadores sin duda, el término conlleva presiones económicas, sociales y de oportunidades que constituyen la forma de vida. WOOLF, E., "Teorías macro y microeconómicas y estrategias familiares: algunas reflexiones ingenuas y escépticas", en Boletín de la Asociación de Demografia Histórica, XII, 2/3 (1994) 11-20.

${ }^{3}$ En cuanto al aspecto familiar, existen obras de referencia como MIKELARENA PEÑA, F., "Las estructuras familiares en la España tradicional: geografía y análisis a partir del censo de 1860", en Boletín de la ADEH, X, 3, (1992) 15-61. MUÑOZ LÓPEZ, P., Sangre, amor e interés: La familia en la España de la Restauración, Madrid, Marcial Pons, 2001. REHER, D. S., La
} 
A pesar del número de estudios dedicados a estos ámbitos, las investigaciones relacionadas con la ciudad de Segovia son escasas. La atención mostrada a otras localidades españolas, en el caso de la capital castellana se reduce a un par de referencias de carácter general, utilizando datos parciales u oficiales ${ }^{4}$ o ya obras más extensas, tanto de contenido como de cronología ${ }^{5}$. La atracción de los historiadores hacia otros aspectos concretos ${ }^{6}$, junto con la dificultad de trasladar los estudios pormenorizados de las hojas de empadronamiento a un núcleo urbano, explican esta ausencia.

En el momento que reducimos el prisma de observación y nos centramos en parroquias y calles estas faltas son más evidentes. Por esto motivos, se hace imprescindible la utilización de lo micro para poder establecer a un nivel cercano el funcionamiento de los diferentes componentes hasta ahora pasivos de la

familia en España. Pasado y Presente, Madrid, Alianza Universidad, 1996. Por su parte, sobre la importancia de los movimientos migratorios y su relación con el mercado de trabajo o la tipología familiar ver GARCÍA ABAD, R., Historias de emigración. Factores de expulsión y selección de capital humano en la emigración a la Ría de Bilbao (1877-1935), Bilbao, Universidad del País Vasco, 2005. GONZÁLEZ PORTILLA, M. y ZÁRRAGA, K., Los movimientos migratorios en la construcción de las sociedades modernas, Bilbao, Universidad del País Vasco, 1996. CARBALLO, B., PALLOL, R., y VICENTE, F., El ensanche de Madrid. Historia de una capital, Madrid, Editorial Complutense, 2008. DE LA FUENTE NÚÑEZ, R., Evolución Histórica de Segovia (1900-1936), Trabajo Académico de Tercer Ciclo, Universidad Complutense de Madrid, 2007. DE LA FUENTE NÚÑ̃EZ, R., La ciudad dependiente: el lento caminar de una ciudad de interior. Segovia 1860-1930, Tesis Doctoral, Universidad Complutense de Madrid, 2016. SAN ANDRÉS CORRAL, J., Guadalajara (1869-1884). El lento despertar de un prolongado letargo, Trabajo Académico de Tercer Ciclo, Universidad Complutense de Madrid, 2007.

${ }^{4}$ Las obras de GARCÍA SANZ, A., "Sobre la población de Segovia durante la Restauración (1870-1900)", en JOVER, J. M. (Ed.), El siglo XIX en España: doce estudios, Barcelona 1974, pp. 397-432, o MARTÍNEZ DE PISÓN, E., Segovia. Evolución de un paisaje urbano, Madrid, Colegio de Ingenieros de Caminos, Canales y Puertos, 1976.

${ }^{5}$ DE LA FUENTE NÚÑ̃EZ, R., La ciudad dependiente..., o.c.

${ }^{6}$ CHAVES MARTÍN, M. A., Arquitectura y Urbanismo en la ciudad de Segovia 17501950, Segovia, Cámara de la Propiedad Urbana de Segovia, 1998. DE LA FUENTE NÚÑ̃Z, R., "De la mendicidad a las instituciones de beneficencia en el primer tercio del siglo XX en Segovia", en Estudios Segovianos, 107 (2007) 159-186. DE LA FUENTE NÚÑEZ, R., "La pobreza como cuestión social y reflejo económico de una ciudad de interior: Segovia en la segunda mitad del siglo XIX", en Anuario Jurídico y Económico Escurialense, 53 (2020) 259-288. DE LA FUENTE NÚÑEZ, R., "El mercado de trabajo femenino en una ciudad de interior: Segovia 18601905", en Investigaciones Históricas, época moderna y contemporánea, Universidad de Valladolid, 40 (2020) 383-418. DE LA FUENTE NÚÑEZ, R., "La maldición de Herodes. Aproximación al trabajo infantil en la ciudad de Segovia 1860-1930”, en Anuario Jurídico y Económico Escurialense, 54 (2021) 459-484. DE LA FUENTE NÚÑEZ, R., "Cuando la muerte viene a visitarte: el paso de la gripe de 1918 y 1919 por la ciudad de Segovia”, en Asclepio, Consejo Superior de Investigaciones Científicas (CSIC), 73(1), (2021) 449-462. DE LA FUENTE NÚÑEZ, R., "El establecimiento Provincial de Beneficencia de Segovia: desde sus orígenes hasta el inicio de la guerra civil española 1836-1936", en Historia Social, (2022) (en prensa). 
ciudad $^{7}$. De esta forma, el objetivo de este artículo es establecer un estudio de la población de Segovia desde 1860 a 1905, desglosándola en su número, origen, características, evolución, estructuras familiares y distribución de la ciudad a través de las diferentes parroquias que componían la capital, tanto aquellas situadas en intramuros, arrabales unidos como separados, reflejando una clara segregación horizontal y vertical del espacio urbano. Para ello, se ha basado en el estudio exhaustivo y total de los padrones municipales mejor conservados en el archivo municipal de Segovia (AMS) de 1860, 1881 y 1905 , archivo del juzgado municipal de Segovia (AJMS), arbitrios sobre inquilinatos, expedientes administrativos municipales, tarifas y salarios profesionales, matrículas industriales, fuentes contemporáneas y prensa local, entre otras. De esta manera, se realiza una radiografía demográfica y socioeconómica de la capital que además pueda ser comparada con otros núcleos nacionales.

\section{LA POBLACIÓN DE SEGOVIA 1860-1905}

Reinhard y Armengaud establecieron el inicio del ciclo demográfico moderno hacia $1870^{8}$, aunque algunos autores lo retrasaron a 1900. David Reher, en cambio, señaló que la urbanización en España se asentaba, hasta esa misma fecha, sobre comportamientos de tipo antiguo. Estos estaban caracterizados por unas tasas de mortalidad altas que producían un crecimiento vegetativo negativo, sólo compensado por una fuerte inmigración, mientras que, en Europa, la transición demográfica estaba prácticamente concluida ${ }^{9}$. Para Segovia, el periodo de la Restauración se manifestó dentro de una etapa de cambio estructural, al final de este, la población apareció configurada de acuerdo con los parámetros de la modernidad. Pero hubo que esperar al fin de la primera guerra europea para que el proceso se consumara ${ }^{10}$.

Segovia en un primer momento aumentó su vecindario de manera considerable, para estancarse a finales del siglo. En 1860 tenía 8.844 habitantes,

${ }^{7}$ OTERO CARVAJAL, L. E., "La reducción de la escala y la narratividad histórica", en Cuadernos de Historia Contemporánea, vol. Extraordinario (2007) 245-264.

${ }^{8}$ ARMENGAUD, A., y REINHARD, M., Historia de la población mundial, Barcelona, Ariel, 1966. Para conocer el "modelo español", diferencial al modelo demográfico europeo, consultar: NADAL, J., Historia de la población española (siglos XVI a XX), Barcelona, Ariel, 1984. También son interesantes obras como la de PÉREZ MOREDA, V. y REHER, D. S., La demografia ..., o.c. PÉREZ MOREDA, V., "La población", en FERNÁNDEZ GARCÍA, A. (Coord.), Historia de España de Menéndez Pidal. Los fundamentos de la España Liberal (1834-1900): sociedad, economía y las formas de vida, dirigida por JOVER, J. Ma , Tomo XXXIII, Madrid, Espasa-Calpe, 1997.

9 REHER, D. S., "Urbanization and demographic behaviour in Spain, 1860-1930", en VAN DER WOUDE, A., DE VRIES, J., y HAYAMI, A., Urbanization in History. A process of dynamic interactions, Nueva York, Clarendon Press-Oxford, 1990, pp. 282-299.

${ }^{10}$ GARCÍA SANZ, o.c., pp. 397-432. 
pasando a 11.455 en 1881, con un índice de crecimiento del 29,52\%, para en los años siguientes mostrar una ligera recesión. En 1905 la capital albergó a 12.726 individuos ${ }^{11}$, teniendo una tasa de crecimiento en estos últimos veinticinco años del $11,09 \%$. Como se puede comprobar en la figura 1, en los primeros veintidós años (1860-1881) la población se desarrolló el doble para desacelerar en los últimos veinticinco años de la centuria.

Figura 1. Evolución de la población de Segovia capital 1857-1905

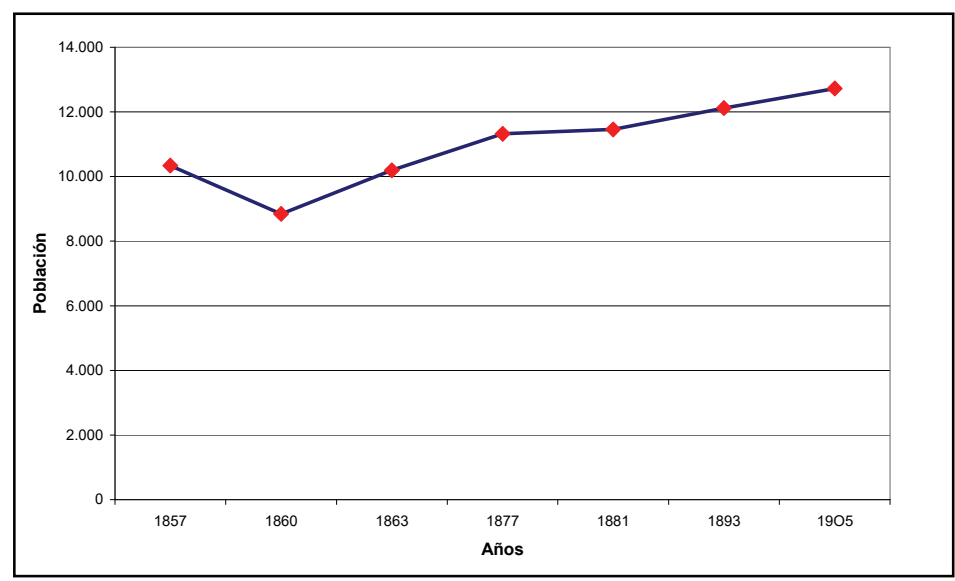

Fuente: AMS. Padrones municipales de la ciudad de Segovia de 1860, 1881 y $1905^{12}$.

Entre 1857 y 1863 se notó ligeramente un descenso demográfico, teniendo su punto más bajo de todo el periodo en 1860. Fue un quinquenio de sucesión continua de saldos positivos con negativos, donde a la larga predominaron los negativos. La evolución de la población se vio truncada por la crisis de subsistencia de los años 1857-1859. Las crisis agrarias repercutían de una forma más directa sobre el interior que en aquellos lugares que tenían conexión al mar. En el centro, prácticamente nada se podía hacer para impedir que ciertas personas acapararan todos los productos con su consecuente inflación. En cambio, en las zonas costeras, al tener la posibilidad de poder importar productos de fuera, la competencia era más lícita, bajando los precios ${ }^{13}$.

${ }^{11}$ AMS. Padrones municipales de Segovia de 1860, 1881 y 1905.

${ }^{12}$ La población correspondiente con los años 1857, 1863 y 1877 ha sido obtenida de GARCÍA SANZ, o.c., pp. 397-432. Por su parte, el dato de 1893 ha sido adquirido del periódico El Faro de Castilla, quién se hizo eco de una publicación oficial del Ayuntamiento de Segovia. Ver el 19 de enero de 1893, número 253, año VI.

${ }^{13}$ Ver ANES, G., Las crisis agrarias en la España moderna, Madrid, Taurus, 1970. GARRABOU, R. (Ed.), La crisis agraria de fines del siglo XIX, Barcelona, Crítica, 1988. SÁNCHEZ-ALBORNOZ, 
En la villa de Riaza [Segovia], ha estado expuesto a que ocurriera un incidente muy desagradable, si con oportunidad no hubieran acudido la Guardia civil (...). Parece ser que la causa del motín fue la subida que experimentó el precio de los cereales, habiéndose presentado en aquel mercado acaparadores con el objeto de acopiar todo cuanto grano pudieran ${ }^{14}$.

A partir de 1860 la población aumentó destacadamente hasta el año 1877. En 1863 la tasa de natalidad en Segovia estaba en un 35,2 por mil y la de mortalidad en un 35,3 por mil, teniendo un crecimiento vegetativo ligeramente negativo. En el año siguiente, la tasa de natalidad subió al 36,8 por mil y la de mortalidad al 35,2 por mil, con un crecimiento vegetativo positivo. Como hemos visto, el saldo entre la tasa de mortalidad y natalidad para 1863 fue de menos 0,1 por mil, mientras que para el año 1864 era de 1,6. Por su parte, para el resto del territorio español en las mismas fechas el saldo fue de 9 y 8 por mil respectivamente, estando la ciudad por debajo de las expectativas nacionales ${ }^{15}$.

Hasta 1870 Segovia arrastró una situación demográfica propia del ciclo demográfico antiguo: número de nacimientos por debajo de fallecimientos, no solamente debido a la mortalidad catastrófica, sino también a la ordinaria $\mathrm{y}$, como no, a la elevada tasa de mortalidad infantil.

De 1877 a 1881 hubo un ligero estancamiento, creciendo levemente hasta 1905. Es un periodo en alza gracias al aumento de nacidos, pero, sobre todo, a la emigración recibida. Los grandes azotes de la población en estos años fueron el sarampión de 1883 y el cólera de 1885, rematando con la mal llamada gripe española de 1918-1919 ${ }^{16}$. El sarampión fue indudablemente la acción más mortífera de cuantas incidieron sobre los párvulos de forma intermitente e irregular. Afectó a los niños entre los dos meses y los cuatro años, estando el punto álgido entre los dos y tres años de vida, alcanzando prácticamente la centena de fallecidos. Respecto al cólera, de los 226 fallecidos registrados, atacó más a los grupos de población comprendidos entre los años 0-4, 30-39 y 6569 , castigando más a las parroquias situadas en los arrabales de la ciudad que a las feligresías de intramuros debido, sobre todo, al desvalimiento económico de los habitantes que ocupaban dichas zonas, convirtiéndoles en presas más fáciles del contagio en relación con las pudientes feligresías urbanas. La parroquia

N., Las crisis de subsistencias de España en el siglo XIX, Rosario, Instituto de Investigaciones Históricas, 1963.

${ }^{14}$ El Liberal Dinástico, 19 de febrero de 1898, número 39, año II, p. 3.

${ }^{15}$ GARCÍA SANZ, o.c., pp. 404 y ss.

${ }^{16}$ DE LA FUENTE NÚÑEZ, R., "Cuando la muerte viene a visitarte..., o.c., pp. 449-462. 
de San Martín, acomodada donde las hubiera, no registró ni un solo fallecido por cólera salvo la de un jornalero que estaba preso en la cárcel de la ciudad situada en la jurisdicción de esta rectoría ${ }^{17}$.

A la altura de 1900 la población de la ciudad siguió creciendo de manera lenta, pero por encima de las tasas del resto de España. Segovia tenía una tasa de natalidad y mortalidad en 1900 de 37,1 y 30,7 por mil respectivamente, con un crecimiento vegetativo del 6,4 por mil ${ }^{18}$. Según Nadal, para el mismo año, la tasa de natalidad y de mortalidad en España se situaba en un 33,8 y 28,8 por mil respectivamente, con un crecimiento vegetativo del 5 por mil ${ }^{19}$, cifras muy lejos de países europeos. Para este mismo año, la tasa de mortalidad de Inglaterra o Francia, por ejemplo, se situaba en 17,2 y 20,6 por mil respectivamente $^{20}$.

Si hacemos balance de estos años vemos como la población aumentó en un $28,14 \%$. Esta crecida fue debido a un incremento de la emigración dirigida hacia la ciudad ${ }^{21}$. Los datos obtenidos de defunciones y bautismos de cinco parroquias no reflejaron ninguna mejora a favor de estos. Tampoco las curvas contrastadas de mortalidad adulta e infantil mostraron reacción singular. La vigencia del ciclo demográfico antiguo, incapaz de instrumentar un ritmo de crecimiento importante y sostenido, parece evidente ${ }^{22}$. Por este motivo no es de extrañar que las urbes españolas fueran vistas como auténticos sepulcros de la especie humana [donde] quedarían presto desiertas si las gentes que mueren en ellas no se substituyesen por las que concurren de los demás pueblos ${ }^{23}$.

\subsection{Origen de la población}

La segunda mitad del siglo XIX fue testigo del desarrollo demográfico de Segovia gracias a la llegada de nuevos habitantes. Según el padrón municipal de 1860 el vecindario estaba compuesto por 8.844 individuos, de los que 5.423 (el $61,32 \%$ ) eran oriundos de la ciudad. A medida que se acercaba el nuevo

${ }^{17}$ AJMS. Partidas de defunción del Registro Civil de Segovia de 1883 y 1885.

${ }^{18}$ GARCÍA SANZ, o.c., p. 412.

${ }^{19}$ NADAL, o.c., pp. 561-741.

${ }^{20}$ SAUVY, A., "Factores sociales de la mortalidad", en Estudios Demográficos, IV (1959) 459.

${ }^{21}$ Todavía la mortalidad superaba a la natalidad haciendo que la emigración fuera la culpable de este crecimiento demográfico. Ejemplo de esta situación fue el artículo publicado por $L a$ tempestad, en el que indicaba que, desde el 1 de enero hasta el 30 de junio de 1883, hubo 260 nacimientos por 376 fallecidos. Ver el 8 de julio de 1883, tormenta 148, año III.

${ }^{22}$ GARCÍA SANZ, o.c., pp. 413 y ss.

${ }^{23}$ ARTETA, A., Disertación sobre la muchedumbre de niños que mueren en la infancia, y modo de remediarla, Zaragoza, I, 1802, p. 129. 
siglo esta diferencia se fue recortando a favor de los foráneos. Como se observa en la tabla 1, la población inmigrante ganó 17,82 puntos en la segunda mitad del siglo XIX, en decaimiento de la local, que perdió un 15,07\%. En el periodo comprendido entre 1860 y 1881 tuvieron lugar un mayor número de cambios que entre 1881 y 1905 . En esta primera etapa, los autóctonos bajaron hasta ocupar el 49,39\%. A partir de 1881 siguió descendiendo de forma paulatina, alcanzando cuotas del 46,25\%. A diferencia de los capitalinos, los inmigrantes crecieron de forma considerable en los primeros veinte años. Si en 1860 representaban apenas el 35,80\%, en 1881 aumentaron al 50,09\% para llegar al 53,62\% en 1905 .

Tabla 1. Evolución de la población de Segovia 1860-1905

\begin{tabular}{|l|c|c|c|c|c|c|}
\hline \multirow{2}{*}{ Origen } & \multicolumn{6}{|c|}{ Años } \\
\cline { 2 - 7 } & \multicolumn{2}{|c|}{1860} & \multicolumn{2}{c|}{1881} & \multicolumn{2}{c|}{1905} \\
\cline { 2 - 7 } & Número & $\%$ & Número & $\%$ & Número & $\%$ \\
\hline $\begin{array}{l}\text { Población } \\
\text { autóctona }\end{array}$ & 5.423 & $61,32 \%$ & 5.657 & $49,39 \%$ & 5.886 & $46,25 \%$ \\
\hline $\begin{array}{l}\text { Población } \\
\text { inmigrante }\end{array}$ & 3.166 & $35,80 \%$ & 5.738 & $50,09 \%$ & 6.824 & $53,62 \%$ \\
\hline $\begin{array}{l}\text { Población } \\
\text { desconocida }\end{array}$ & 255 & $2,88 \%$ & 60 & $0,52 \%$ & 16 & $0,12 \%$ \\
\hline Total & 8.844 & $100 \%$ & 11.455 & $100 \%$ & 12.726 & $99,99 \%$ \\
\hline
\end{tabular}

Fuente: AMS. Padrones municipales de Segovia de 1860, 1881 y 1905.

Dentro de esta emigración, destacó claramente la llegada de población rural procedente de la provincia, por encima de la originaria del resto de España. Como se puede apreciar en la tabla 2, durante todo el periodo estudiado estuvo en niveles cercanos al $60 \%$.

Tabla 2. Clasificación de la población inmigrante de Segovia 1860-1905

\begin{tabular}{|l|c|c|c|}
\hline \multirow{2}{*}{ Lugar de Procedencia } & \multicolumn{3}{|c|}{ Años } \\
\cline { 2 - 4 } & $\mathbf{1 8 6 0}$ & $\mathbf{1 8 8 1}$ & $\mathbf{1 9 0 5}$ \\
\hline Provincia de Segovia & $58,72 \%$ & $67,79 \%$ & $60,01 \%$ \\
\hline Provincias limítrofes & $14,59 \%$ & $14,29 \%$ & $18,76 \%$ \\
\hline Resto de provincias & $26,56 \%$ & $17,74 \%$ & $19,91 \%$ \\
\hline Extranjero & $0,13 \%$ & $0,17 \%$ & $1,32 \%$ \\
\hline
\end{tabular}

Fuente: AMS. Padrones municipales de Segovia de 1860, 1881 y 1905. 
Este porcentaje de población emigrante que llegó a Segovia en la segunda mitad del siglo XIX y principios del XX no se localizó de una manera homogénea, dependía del conocimiento de la parroquia donde se instalaban, ya fuera por el contacto directo con familiares o por vecinos del pueblo de origen o de municipios cercanos al suyo; también del precio del suelo, menor en los arrabales que en el centro amurallado, aunque dentro de este, había zonas donde la concentración de forasteros era elevada, sobre todo, parroquias más populosas u ocupando interiores, porterías o sotabancos. Como se puede ver en la imagen 1, Segovia tenía tres zonas de asentamiento claramente diferenciadas: aquellas situadas en intramuros, quedando cercadas por la antigua muralla de la ciudad; seguidas de las parroquias aledañas, los denominados como arrabales unidos, concluyendo con los barrios más alejados, los arrabales separados.

Imagen 1. Plano de Segovia de 1849

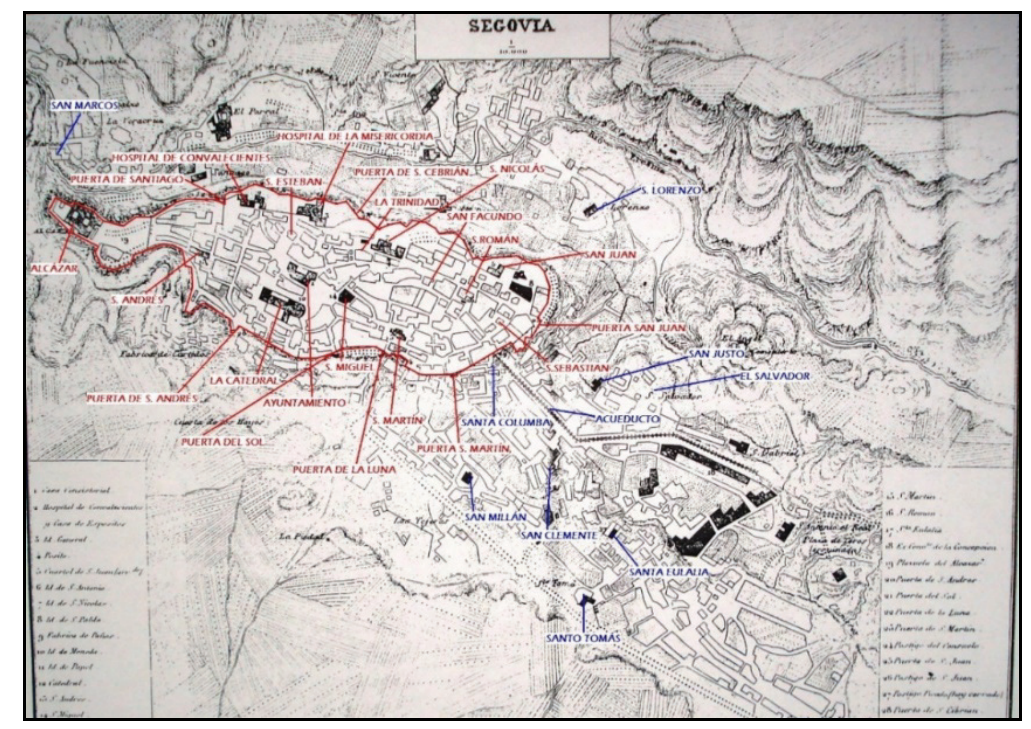

Fuente: Plano de Segovia de Francisco Coello de 1849, escala 1:10.000. Los nombres en color rojo hacen referencia a las partes situadas en intramuros. En color azul, los arrabales.

\section{DISTRIBUCIÓN ESPACIAL DE LA POBLACIÓN SEGOVIANA}

En cuanto a la distribución de la población segoviana por la capital ${ }^{24}$, a finales del siglo XIX hubo un progresivo descenso en intramuros cobrando importancia

\footnotetext{
${ }^{24}$ Antes de iniciar el análisis de la distribución de la población en la ciudad de Segovia hay que dejar claro algunas cuestiones previas. En primer lugar, en el padrón municipal de
} 
los arrabales, particularmente, los unidos. En 1860 el 46,36\% de los vecinos vivían dentro del casco amurallado, pasando a representar el 37,45\% en 1905. Este recorte fue ganado en especial por las parroquias de San Millán, Santa Eulalia y el Salvador, que en apenas cuarenta y cinco años duplicaron su representatividad. No hay que olvidar a los arrabales separados, que a pesar de su escasa importancia con respecto al total de la ciudad (el periodo de mayor auge fue en 1905 ocupando un 10,08\% del total), también crecieron doblando prácticamente sus dimensiones en este periodo estudiado. A medida que nos acercamos al nuevo siglo se asiste a un cambio en la forma de asentamiento, donde primaron más aquellos lugares exteriores que el interior de la ciudad.

Tabla 3. Distribución de la población segoviana en 1860, 1881 y 1905

\begin{tabular}{|c|c|c|c|c|}
\hline Situación & Parroquia & Población 1860 & Población 1881 & Población 1905 \\
\hline \multirow{11}{*}{ Intramuros } & La Catedral & 203 & 341 & 464 \\
\hline & La Trinidad & 155 & 453 & 409 \\
\hline & San Nicolás & 245 & --- & --- \\
\hline & San Miguel & 1.327 & 1.569 & 1.491 \\
\hline & San Andrés & 376 & 463 & 437 \\
\hline & San Martín & 832 & 615 & 813 \\
\hline & San Esteban & 504 & 777 & 703 \\
\hline & San Sebastián & 104 & 517 & 449 \\
\hline & San Román & 65 & --- & --- \\
\hline & San Juan & 104 & --- & --- \\
\hline & San Facundo & 185 & $\begin{array}{ll}-- \\
-\end{array}$ & --- \\
\hline \multicolumn{2}{|c|}{ Total intramuros } & $4.100(46,36 \%)$ & $4.735(41,33 \%)$ & $4.766(37,45 \%)$ \\
\hline \multirow{7}{*}{$\begin{array}{l}\text { Arrabales } \\
\text { unidos }\end{array}$} & Sta. Columba & 682 & 826 & 810 \\
\hline & San Clemente & --- & 538 & 573 \\
\hline & San Millán & 674 & 1.030 & 1.108 \\
\hline & Santa Eulalia & 1.183 & 1.454 & 1.945 \\
\hline & Santo Tomás & 729 & 683 & 898 \\
\hline & El Salvador & 447 & 585 & 870 \\
\hline & San Justo & 311 & 555 & 473 \\
\hline \multicolumn{2}{|c|}{ Total arrabales unidos } & $4.026(45,52 \%)$ & $5.671(49,51 \%)$ & $6.677(52,47 \%)$ \\
\hline \multirow{2}{*}{$\begin{array}{l}\text { Arrabales } \\
\text { separados }\end{array}$} & San Lorenzo & 597 & 806 & 1.042 \\
\hline & San Marcos & 121 & 243 & 241 \\
\hline \multicolumn{2}{|c|}{ Total arrabales separados } & $718(8,12 \%)$ & $1.049(9,16 \%)$ & $1.283(10,08 \%)$ \\
\hline \multicolumn{2}{|l|}{ TOTAL } & $8.844(100 \%)$ & $11.455(100 \%)$ & $12.726(100 \%)$ \\
\hline
\end{tabular}

Fuente: AMS. Padrones municipales de Segovia de 1860, 1881 y 1905.

1860 la parroquia de San Clemente estaba incluida en la de Santa Columba, apareciendo separada a partir de 1881. En el padrón de 1881 desaparecieron las parroquias de San Román, San Juan y San Facundo, que pasaron a estar englobadas en la de San Sebastián, menos la calle del Serafín que fue adscrita a la parroquia de la Trinidad. Por último, la parroquia de San Nicolás, a partir de 1881 también quedó incluida en la de La Trinidad. 
Este hecho no tuvo nada de casual, pues respondía a la llegada de inmigrantes de carácter provincial, quién aprovechando viejos contactos se instalaron cerca de sus conocidos. Hubo un cambio de tendencia en la evolución de la población debido a la estratificación social de forma horizontal, donde las personas abandonaban las zonas interiores para instalarse en la periferia. Del pueblo segoviano de Zarzuela del Pinar tenemos varios ejemplos, como eran las familias Callejo. Unos son los Callejo Lobo, otros los Callejo Martín y los últimos simplemente, Callejo.

Los hermanos Callejo Lobo dejaron el medio rural para ir a Segovia en busca de una oportunidad laboral. El primero que llegó a la ciudad fue Santiago Callejo Lobo para trabajar como curtidor. En 1881 estaba casado con Tomasa Martín de Pablos, conocida del pueblo. Vivía con ellos un familiar, Aureliano Martín Escribano, de apenas siete años. Tenían su residencia en la calle de Arcos número 16, en la parroquia de San Millán (arrabales unidos) y llevaban viviendo en Segovia tres años. En la misma rectoría, cercana a la casa de Santiago, en Arcos 11, vivía la familia de Manuel Callejo Lobo, hermano de Santiago; de profesión curtidor, estaba casado con Dominica Criado Pérez, natural de Zarzuela del Pinar. Tenían dos hijos: Juan, nacido en Zarzuela y Pedro, en Segovia. Padres y primogénito a la altura de 1881 llevaban viviendo tres años en la capital. Por si fuera poco, tenían que ayudar a los padres de Dominica, Mariano y Petra que, tras una mala racha, habían caído en la mendicidad ${ }^{25}$.

Al año de llegar a la ciudad, lo hicieron dos hermanos más, Indalecio y Enrique. El primero de ellos encontró aposento en la misma casa que Santiago, en Arcos 16. En 1881 trabajaba también de curtidor ${ }^{26}$ y estaba casado con Felipa Maderuelo Calvo, de Zarzuela del Pinar. Tenían cuatro hijos: Lorenzo, Gregoria, Juan y Bonifacio, de siete, seis, cuatro y dos años respectivamente, todos ellos nacidos en el pueblo. Por su parte, Enrique, el cuarto de los hermanos, arribó a la vez que Indalecio. Se estableció en la calle del Carmen, perteneciente a la parroquia de San Clemente (cercano a los otros hermanos). Ejercía de jornalero y estaba casado con Petra Guijarro Pérez, también de Zarzuela. A la altura de 1881 tenían tres hijos: Gil, Segunda y Martina, los dos primeros nacidos en el pueblo y el tercero, ya en la ciudad ${ }^{27}$.

La llegada a Segovia no fue fruto del azar, pues ya había antiguos paisanos suyos viviendo en la ciudad. A pesar de que los últimos Callejo Lobo al arribar a la capital ya tenían a sus otros dos hermanos instalados, los dos primeros

\footnotetext{
${ }^{25}$ Así se declaraban en el padrón municipal de Segovia de 1881.

${ }^{26}$ En el padrón municipal de Segovia de 1905 aparece ya como jornalero. AMS.

${ }^{27}$ AMS. Padrones municipales de Segovia de 1881 y 1905.
} 
tampoco estaban solos. Hay un Callejo Martín y bastantes Callejo del pueblo de Zarzuela del Pinar viviendo en San Millán y en las parroquias aledañas, ejerciendo el mismo oficio de curtidor $^{28}$. Por lo que el viaje tenía poco de improvisación y mucho de esa red familiar tan característica de los procesos migratorios, tanto en la provincia de Segovia por parte de los varones como en el caso de las mujeres ${ }^{29}$, coincidiendo a la perfección con una realidad que se venía reproduciendo en otros núcleos españoles ${ }^{30}$.

Por otro lado, el despoblamiento progresivo del centro histórico también tuvo que ver con los nuevos ideales burgueses. Uno de los principales objetos de ostentación fue la posesión y magnificencia de la casa, lo que Otto Brunner denominó como la casa grande $e^{31}$. En el momento en el que se amplían las nuevas parroquias de la ciudad, aquellas aledañas a intramuros, como era el caso de San Clemente o Santa Columba, con mayor comodidad y espacio, grandes familias trasladaron allí su residencia, poniendo tierra de por medio entre los servidos y los servidores. Tampoco hay que olvidarse de las instituciones religiosas, que buscaron nuevas zonas más alejadas y tranquilas de la ciudad para ejercer sus actividades espirituales. Dentro del recinto de los muros faltaba espacio a las comunidades religiosas para dilatarse ya desde los tiempos más inmediatos a la Restauración; así es que aun las más antiguas se fijaron en los arrabales ${ }^{32}$.

\section{INTRAMUROS}

\subsection{Parroquia de la Catedral}

Parroquia pequeña, de gran importancia religiosa, ya que contenía el principal edificio eclesiástico de la ciudad y el convento de religiosas las Siervas de María ubicado en la Canonjía Nueva número 11. Su vecindario se duplicó en esta

${ }^{28}$ Los curtidores eran aquellas personas que trabajaban las pieles. Para conocer la importancia que tenía este gremio ver la obra de ESCUDER, C. B., Manual del curtidor y nociones de peletería, Madrid, Espasa Calpe, 1935.

${ }^{29}$ DE LA FUENTE NÚÑEZ, R., "El mercado de trabajo femenino..., o.c., pp. 383-418.

${ }^{30}$ Estas redes familiares además de ser las controladoras del proceso migratorio, establecían las pautas y formas de producirse la emigración. García Abad también establece como eran los hermanos quién iniciaban la cadena. Primero emigraba un individuo, bien solo o con su familia, posteriormente iba recibiendo a sus hermanos, trasladándose a los mismos destinos, e incluso, dedicándose a las mismas profesiones. Ver GARCÍA ABAD, R., "Las redes migratorias entre el origen y la Ría de Bilbao a finales del siglo XIX: una aproximación metodológica", en Revista de Demografia Histórica, XX, I (2002) 21-51.

31 Término recogido por MUÑOZ LÓPEZ, P., Sangre, amor e interés, o.c., p. 434.

${ }^{32}$ QUADRADO, J. Ma ., Salamanca, Ávila y Segovia, Barcelona, Editorial de Daniel Cortezo y Compañía, 1884, p. 657. 
mitad del siglo XIX, pasando de 203 personas en 1860 a 464 en 1905 , con un índice de crecimiento del $128 \%$. Una de las causas fue la instalación de un cuartel de la guardia civil en la plazuela del Alcázar, que en 1881 contaba con más de sesenta efectivos. La emigración fue otra gran responsable del aumento poblacional, ocupando el 65,02\% en 1860 y el 68,32\% en 1905 .

Parroquia de religiosos, militares y del servicio doméstico. En 1860 había cincuenta y una personas dedicadas al servicio doméstico y cincuenta y cuatro en 1881. En 1905 el número de sirvientes era de diecinueve, coincidiendo esta bajada con el crecimiento de puestos en la administración. Por otro lado, apreciamos un cambio considerable en la estructura familiar de las viviendas. Si en 1860 las familias nucleares ocupaban solamente el $35,71 \%$ del total de la parroquia, en 1881 era del $66,68 \%$, creciendo hasta el $76,41 \%$ en 1905 .

\subsection{Parroquias de la Trinidad y San Nicolás}

Todavía en 1860 la iglesia de San Nicolás figuraba con sus feligreses; a finales del siglo XIX fue convertida en taller de teatro ${ }^{33}$. Tras su desuso, su población fue anexionada por la parroquia de La Trinidad. Destacaba la presencia del hospital de la Misericordia, administrado por las hermanas de la Caridad y con capacidad para 218 camas $^{34}$, la mayoría de ellas para personas ancianas, repartidas en siete salas para los hombres y una para las mujeres ${ }^{35}$. También estaba el convento de Convalecientes ${ }^{36}$ y la casa de beneficencia, que en 1860 tenía sesenta y ocho empadronados ${ }^{37}$. En el padrón de 1905 aparece otra institución benéfica, denominada El Refugio ${ }^{38}$. Por último, el corralillo de San Nicolás, recinto cerrado con varias casas dedicadas a viviendas de gente jornalera y humilde.

${ }^{33}$ A finales del siglo XIX aparecían en la prensa local diversos artículos denunciando el estado de abandono en el que se encontraba el edificio, haciendo saber a las autoridades el peligro que presentaba a los viandantes y reclamando una solución para la antigua iglesia. Ver entre otros El Liberal Dinástico, 15 de mayo de 1897, número 2, año I, p. 3.

${ }^{34}$ MADOZ, P., Segovia. Diccionario Geográfico Estadístico Histórico 1845-1850, Valladolid, Diputación Provincial de Segovia, 1998, p. 201. Edición facsímil.

${ }^{35}$ Fundado tras varios sucesos en 1564. Los enfermos que en él se hallaban estaban bien asistidos tanto en lo espiritual como en lo temporal, pero sujetos a reglamentos particulares que limitaban la clase de enfermos admisibles, estando muy lejos de cubrir las necesidades de la población. Ver LOSAÑEZ, J., El alcázar de Segovia, Segovia, imprenta de Pedro Ondero, 1861 , pp. 252 y ss.

${ }^{36}$ Mandado fundar por el médico Juan Núñez de Riaza, para acoger a los que todavía salían débiles del hospital de la Misericordia. Empezaron a recibir pobres a partir de 1608. Ver LOSAÑEZ, o.c., p. 254.

${ }^{37}$ Sesenta y cinco niñas, dos niños y una nodriza. AMS. Padrón municipal de Segovia de 1860.

${ }^{38}$ Fundada en junio de 1891. Su función era la de dar posada al peregrino. DE LA FUENTE NÚÑEZ, R., "La pobreza como cuestión social..., o.c., pp. 259-288. 
$\mathrm{Su}$ vecindario se mantuvo prácticamente estable, alcanzando su cenit en 1881 con 453 personas. A diferencia de la parroquia de la catedral, su población inmigrante creció de forma espectacular en los primeros años. Si en 1860 representaba el $31,25 \%$ con respecto a la local, en 1881 pasó al 59,38\%. Una afluencia predominantemente provinciana, que con la llegada de la nueva centuria se igualó a la procedente del resto de España. En 1860 el 64\% de la emigración provenía de los pueblos de la provincia, manteniéndose en 1881, bajando hasta el 55\% en 1905 .

Parroquia de sirvientes, jornaleros y de oficios en esta segunda mitad del siglo XIX. Los sirvientes mantuvieron prácticamente su número (veintisiete en 1860 y treinta y dos en 1881) para caer drásticamente a la media docena en 1905. Por su parte, los jornaleros iniciaron un crecimiento considerable, pasando de diecisiete en 1860 a cuarenta y cinco en 1905 . También era lugar de residencia de un nutrido número de oficios (siete zapateros, tres sastres, cinco carpinteros, un sombrerero...), que a principios del siglo XX prácticamente desaparecieron en beneficio de los empleados; en 1905 residían en esta parroquia un total de dieciocho.

Lugar de contrastes y de clara segregación vertical. Los precios de 75 pesetas que podían costar un piso de tipo principal no podían ser soportados por los sueldos precarios de los recién llegados, estando el salario de jornalero entre una con cincuenta y dos pesetas diarias, siendo lo normal una setenta y $\operatorname{cinco}^{39}$; y el del servicio doméstico, remunerado muchas veces con el alojamiento y manutención. De esta forma, se hacía necesario el trabajo y la colaboración de todos los miembros de la casa, sin importar género o edad ${ }^{40}$. Unos, alojados en las casas o lugares donde servían, otros, por su parte, ocupando sotobancos, buhardillas, porterías o interiores. Por último y a diferencia de la parroquia de la catedral, había un predominio claro de unidades familiares nucleares. En 1860 y 1881 el porcentaje era del 68\% y 69\% respectivamente, creciendo hasta el 73\% en 1905.

\subsection{Parroquia de San Miguel}

Estamos ante la parroquia de mayor población dentro del recinto amurallado. En 1860 contaba con 1.327 personas empadronadas en esta feligresía, aumentando hasta las 1.569 en 1881, mostrando un índice de crecimiento del 18,24\%; dismi-

\footnotetext{
${ }^{39}$ AMS. Precio medio de los jornales 1894-1904. Expedientes 996-4 y 1.031-10.

${ }^{40}$ DE LA FUENTE NÚÑEZ, R., "El mercado de trabajo femenino..., o.c., pp. 383-418. DE LA FUENTE NÚÑEZ, R., "La maldición de Herodes..., o.c., pp. 459-484.
} 
nuyendo a 1.491 habitantes en 1905. Englobaba zonas tan importantes como la plaza de la Constitución (uno de los lugares de concentración profesional de la ciudad), el convento del Corpus Christi o el de los Padres de la Orden de San Francisco, en la calle del Sol 14.

Entre todos los edificios de la plaza (...) sobresalen dos: un caserón de piedra, apoyado sobre columnas de las que forman los portales largos, $y$ una iglesia. El caserón de piedra tiene unas enormes rejas y un enorme balcón, dos torrecillas y un reloj. La iglesia es la de San Miguel, edificada en parte del terreno que ocupaba otra de la misma advocación que se derrumbó. En la fabricación del nuevo templo se emplearon los materiales del antiguo. El edificio del reloj no podría ser otro que la casa del Ayuntamiento ${ }^{41}$.

La emigración que acogió en este periodo apenas varió; en 1860 era del $48,83 \%$ y en 1905 el 50,84\%, procedente principalmente de los pueblos de la provincia. En 1881 llegó a representar el 77\% de la emigración recibida, bajando hasta el 57\% en 1905.

Parroquia en la que estaban representados el mundo de los oficios, los cargos de la administración de la ciudad y, en gran medida, el mundo de la hostelería y del servicio doméstico. En el padrón de 1860 aparecen en esta parroquia más de doscientas personas declaradas como sirvientes y al menos cien que desempeñaban puestos en mesones, fondas, hoteles..., destacando los catorce taberneros o los nueve posaderos, entre otros.

Por su parte, el precio de los alquileres rondaba entre las 8 pesetas que podía costar un piso interior en la calle Santa Ana a 125 un principal de la calle Isabel la Católica. Por último, el modelo familiar predominante era el nuclear; en 1860 el 55\% de las unidades familiares lo eran, alcanzando el $70 \%$ en 1881 y 1905. También destacaba por la aparición de parientes en las casas.

\subsection{Parroquia de San Andrés}

Parroquia colindante a la Catedral y de reducidas dimensiones. Situada al oeste de la ciudad, contaba con el convento femenino de las Carmelitas Descalzas, que en 1860 estaba ubicado en la plazuela de Isabel II. En este mismo año, el número de empadronados era de 376 , para crecer un $23 \%$ en apenas veinte años. A partir

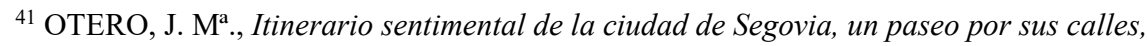
Segovia, 1915, p. 64.
} 
de 1881, su importancia se vio reducida hasta llegar a las 437 personas en 1905 (veintiséis menos que en 1881). Su población inmigrante pasó de representar en 1860 y 1881 un $41 \%$ del total de la parroquia, para prosperar hasta el $62,47 \%$ en 1905. Una afluencia recibida de forma dispar; si en los primeros años hubo un predomino provinciano, a principios de siglo la mayoría procedía del resto de España. En 1881 el porcentaje era del 83\% del total de la emigración recibida en esta parroquia, en 1905 retrocedió hasta el 31\%.

En cuanto a la composición profesional, destacaban por encima del resto el número de jornaleros y de personas que ejercían el servicio doméstico. En 1860 había once jornaleros empadronados, creciendo hasta los cincuenta y ocho en 1905. Por su parte, la servidumbre alcanzó en 1881 los cincuenta representantes. También había propietarios, religiosos, empleados y artesanos, pero en menor medida que los anteriores. Esta amalgama se veía reflejada en las hojas de arbitrios de inquilinato, en la que, como se puede ver en la imagen 1, un bajo era ocupado por un zapatero, compaginando la vivienda con su labor profesional, con un piso principal, en la que el empleado podía hacer frente a las 35 pesetas mensuales, más del doble que el primero. Por su parte, la estructura de los hogares era de carácter nuclear; el 65\% del total de las familias en 1860 y un 73\% en 1905. Este crecimiento coincidió con la disminución del número de acogidos, decreciendo de un 12\% en 1860 a apenas representar un 2\% en 1905.

Imagen 1. Hoja de arbitrios de la calle Doctor Castelo números 10 y 12

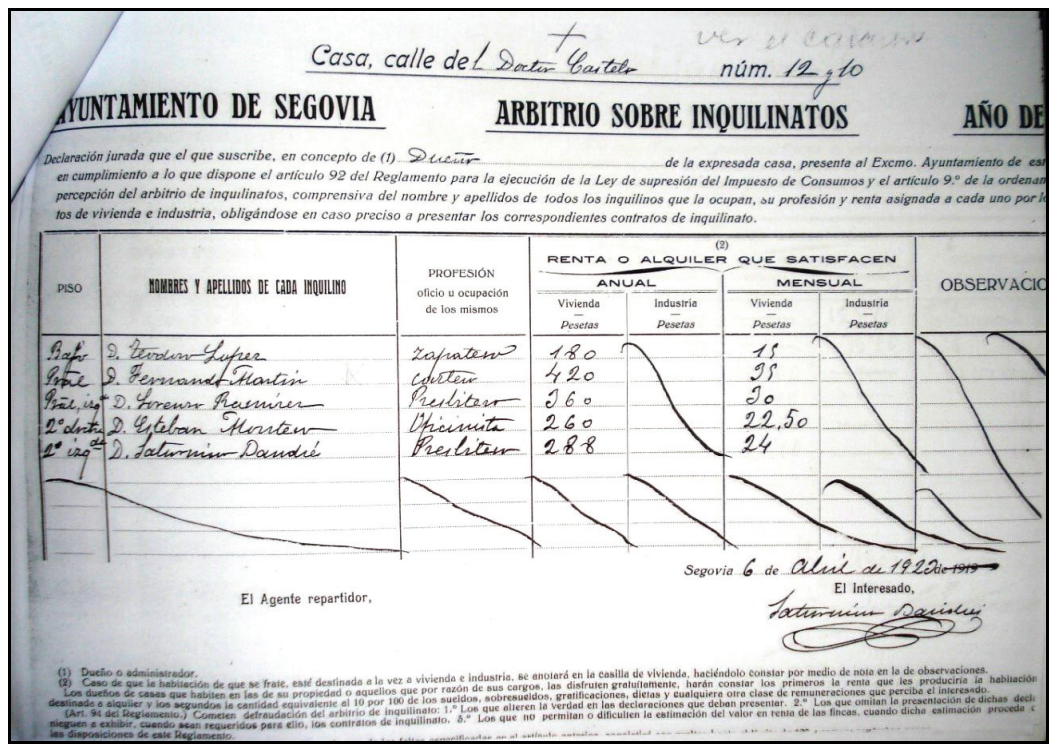

Fuente: AMS. Arbitrios sobre inquilinatos. Expediente 1.356-45. 


\subsection{Parroquia de San Martín}

Era una de las feligresías más acomodadas y pudientes de la ciudad, como así era respaldado por el precio de las viviendas, la mayoría en propiedad o con los alquileres mensuales comprendidos entre las 60 y 90 pesetas. Además de residir religiosos, destacaban los veintinueve propietarios de 1881, las profesiones liberales, como abogados, procuradores, profesores, ingenieros...; zona de residencia de empleados y también de gran número de personas trabajando en el servicio doméstico interno (en 1860 contaba con 135 personas). Característico emplazamiento comercial, lugar de sastres, encuadernadores y de posaderos; contaba con un cuartel de la guardia civil, la cárcel y el seminario conciliar.

Únicamente nuestras pisadas turban el silencio de la calle, la calle principal de una ciudad, la calle en que hay unas puertas (...) el despacho del velonero, del herbolario, la cintería y obradores de unos oficios simpáticos, el obrador del talabartero, del tornero, el del cedacero, el del platero ${ }^{42}$.

Hubo un descenso considerable de sus habitantes; si en 1860 la parroquia tenía 832 personas, en 1881 menguó hasta las 615 para recuperarse en 1905, llegando a alcanzar los 813 efectivos, por debajo de sus cotas iniciales. La población inmigrante que recibió aumentó más en los primeros veinte años. En 1860 contaba con el 49,28\% de emigración respecto al total; en 1881 representó un $57 \%$, estancándose con la llegada del nuevo siglo. El vecindario que acogió, a diferencia de otros barrios, sufrió una variación en cuanto a su origen. En 1860 y 1881 el 54\% de la emigración provenía de los pueblos de la provincia, sin embargo, en 1905 el porcentaje disminuyó a niveles cercanos al 48\%. Por lo que, en el periodo estudiado, la población procedente del resto de España ganó enteros con respecto a la provinciana. Este hecho no tenía nada de casualidad, pues la emigración de los pueblos era mayoritariamente no cualificada, mientras que la que llegaba del resto de España ejercía en cargos más relevantes. De los treinta y ocho guardias civiles que había en el cuartel de la parroquia de San Martín en 1860, solamente cuatro eran naturales de la provincia. Otra de las razones que explicaba el asentamiento de determinados grupos sociales, coincidía con el estado en que se encontraban las viviendas de esta parroquia, siendo de las que en mejores condiciones se hallaban de la ciudad.

En cuanto a la estructura del hogar, dominaba la forma nuclear. En 1860 el 53,52\% estaban agrupadas bajo esta clasificación, mientras que para 1905 este porcentaje subió hasta un $62 \%$. El número de familias extensas, en torno al $10 \%$, era debido a la incorporación de un pariente. Un caso evidente lo

\footnotetext{
${ }^{42}$ OTERO, o.c., p. 70.
} 
evidenciaba Juan Sánchez Varez, natural de Peñaranda (Salamanca); en 1881 aparecía declarado como comerciante y casado con Francisca Callejo Vázquez, no tenían hijos, pero vivían con ellos dos cuñados, Rafaela y Eulogio Callejo, este último trabajando de comerciante con Juan. Además de estos familiares residían la hermana de Juan, Candelas Sánchez (que había llegado a Segovia hacía dos meses) y la suegra, María Vázquez García. Esta mujer aparecía casada en 1860 con Hermenegildo Callejo, quien, tras enviudar, se fue a la casa de su hija Francisca, trasladando su domicilio de la calle de San Francisco 17 a Juan Bravo 5. Además, a la altura de 1905, Eulogio Callejo Vázquez, cuñado de Juan Sánchez, se casó y se llevó a su mujer Aquilina a la misma casa donde moraban todos, a los que se unían tres dependientes del negocio ${ }^{43}$.

\subsection{Parroquia de San Esteban}

Parroquia situada al norte de la ciudad, donde estaban ubicados el palacio episcopal, el convento de Santo Domingo, el de San José y el de San Juan de Dios; la Casa de la Moneda y una institución militar destinada al albergue de estudiantes de la Academia de Artillería. Zona de sirvientes, jornaleros, oficios, empleados, propietarios e incluso pobres (en 1881 aparecían veinticinco personas empadronadas con este "oficio"). Un ejemplo de esta amalgama quedaba reflejado en los alquileres, donde encontramos viviendas como el bajo situado en la calle del Vallejo por 13 pesetas mensuales o, por el contrario, las 80 pesetas que se necesitaban para arrendar el principal de Covarrubias.

Su vecindario aumentó durante los primeros veinte años, para después estancarse. En 1860 contaba con 504 habitantes, ascendiendo hasta los 777 en 1881, mostrando un índice de crecimiento del $54,17 \%$, para después bajar hasta las 703 almas en 1905. El porcentaje emigratorio siguió una línea ascendente de manera suave pero continuada; en 1860 el $42,06 \%$ era emigrante, para crecer hasta el 55,48\% en 1905. Una población llegada tanto del resto de España como de la provincia, salvo en 1881, cuando predominó la segunda sobre la primera con un $63,75 \%$. La composición familiar era de carácter nuclear, estando sus niveles por encima del $60 \%$ en todo el periodo. Destacaban también las familias sin núcleo, en 1860 y 1881 eran del 17\% para crecer a un $23 \%$ en 1905.

\subsection{Parroquias de San Sebastián, San Román, San Juan y San Facundo}

Parroquias unificadas en torno a la de San Sebastián por diferentes suertes. San Juan pasó a ser un taller cerámico, San Román fue víctima de la piqueta

\footnotetext{
${ }^{43}$ AMS. Padrones municipales de Segovia de 1860, 1881 y 1905.
} 
en 1866 y San Facundo fue derribada en 1884, convirtiéndose en un depósito de escombros. A pesar del tiempo transcurrido desde que se efectuó el derribo de la iglesia que alli existía, nadie se ha tomado la molestia de dar las órdenes oportunas para que se arregle $e^{44}$.

Había dos cuarteles, uno arruinado, el convento de las Franciscanas Concepcionistas de la calle Licenciado Peralta número 2 y el edificio del Gobernador Civil, en la plaza del Seminario. Zona de religiosos, militares, algún oficio, numerosos sirvientes en los primeros años y un continuo crecimiento de los jornaleros, contando con cuarenta y tres en 1905. Su vecindario apenas varió. En 1881 alcanzó la cifra de 517 personas (cincuenta y nueve más que en 1860), para disminuir en 1905 hasta 449. En 1860 el porcentaje inmigrante era del $39,74 \%$, cifra baja comparada con los años siguientes. Para 1881 y 1905 la población foránea alcanzó niveles próximos al $60 \%$. Emigración de predominio provinciano con un $58 \%$ en todo el periodo. Fruto de esta situación, nos encontramos con una disparidad en el precio de los alquileres, estando desde las 15 pesetas que costaba arrendar un bajo en la calle Colón hasta las 100 pesetas de Avendaño. Por último, la estructura familiar dominante era la nuclear. En 1860 y 1881 sus niveles eran del 61\% y 67\% respectivamente, en 1905 alcanzó el 77\%.

\section{ARRABALES UNIDOS}

\subsection{Parroquia de Santa Columba}

La parroquia de más prestigio de los arrabales ${ }^{45}$, a pesar de no pertenecer a intramuros por su proximidad podría, ya que lindaba con el recinto amurallado. Comprendía zonas tan importantes como la calle Real del Carmen o la plaza del Azoguejo. Parroquia de industriales, de profesiones liberales, empleados, comercio y oficios, como también de sus sirvientes. Fruto de ello, encontramos alquileres tan altos como eran las 75 pesetas del principal de la calle San Juan; también estaban los modestos bajos o interiores, como el de la calle de San Francisco 38, que por 11 pesetas podían vivir.

Aunque perdió vecindario por la disgregación que sufrió a favor de la parroquia de San Clemente a partir de 1881, no dejó de aumentar. En 1860 contaba con 682 habitantes, para alcanzar 810 en 1905, con un índice de crecimiento del $18,77 \%$. En los años comprendidos entre 1860 y 1881 dominó la emigración

\footnotetext{
${ }^{44}$ La Legalidad, 11 de enero de 1896, número 379, año IX, segunda época.

${ }^{45}$ A pesar del estado de abandono de la iglesia y de su derrumbamiento, su población no se agregó a otras parroquias como los casos de San Román, San Facundo, San Juan o San Nicolás.
} 
provinciana, con unos porcentajes del $56 \%$ y del $82 \%$ respectivamente sobre el total de los forasteros; en cambio, para 1905, se vio superada por la procedente del resto de España con cuotas del 53\%. Por último, la población emigrante provinciana de 1881 superó en número a la de origen capitalino.

La estructura familiar siguió la tónica general, predominio de tipo nuclear por encima del $65 \%$ en todo el periodo, teniendo su punto álgido en 1905 con un $75 \%$ del total. También es de destacar el porcentaje de familias que tenían conviviendo a algún familiar, el 15\% de ellas en 1881, siendo el porcentaje más alto de todas las parroquias segovianas, muestra de la importancia socioeconómica de su población, similar a la de San Martín. En el padrón municipal de 1881 aparece registrada la familia de Mariano del Barrio Cruz, natural de Segovia y de profesión sastre. Estaba casado con Ángela Aceña Dueñas, originaria de las Navas de San Antonio (Segovia). Llegó a Segovia con un año de edad debido a la emigración realizada por sus padres. Tenían tres hijos: Victoria, Bernarda y Eusebio, de trece, diez y un año respectivamente. Vivían en la calle de San Clemente número 7, perteneciente a la parroquia de Santa Columba (arrabales unidos). Además, tenían acogidos al suegro de Mariano, Santos Aceña Ruiz, oriundo de las Navas de San Antonio, que ejercía de quinquillero y a los dos cuñados: Nicolasa Aceña y Felipe Aceña, este último zapatero. Les recogieron en el momento en el que Santos Aceña enviudó de su mujer Feliciana Dueñas y trasladaron su domicilio del corralillo de San Sebastián, adscrito a la parroquia del mismo nombre (intramuros), al de su hija en Santa Columba, buscando amparo y ayudando en la medida de lo posible. En el momento en que pudieran desenvolverse abandonarían el seno familiar para crear su propia familia. En 1905 no hay rastro de nadie salvo de Ángela y Mariano, quien había cambiado la sastrería por un empleo estable y sueldo fijo, convirtiéndose en un envidiable empleado ${ }^{46}$. De esta forma, la presencia de algún familiar, a diferencia de otros hogares, no suponía un revés a la economía doméstica.

\subsection{Parroquia de San Clemente}

Parroquia prácticamente de nueva creación, ya que en el padrón de 1860 estaba adscrita a la de Santa Columba. Zona de tránsito entre esta anterior y otras parroquias más "populosas" como podían ser Santa Eulalia, Santo Tomás o San Millán. El número de empadronados pobres era notable, diecinueve en 1881. Había una casa en la calle de la Asunción tutelada por la Junta de Beneficencia, donde se daba alojamiento a viudas pobres; en el padrón de 1881 aparecían trece empadronadas.

\footnotetext{
${ }^{46}$ AMS. Padrones municipales de Segovia de 1860, 1881 y 1905.
} 
Es un refugio abierto por la caridad para los últimos días de unas ancianas desvalidas. En un patio reducido y desigual se alza una capilla, y a su abrigo agrúpense hasta una docena de puertas bajas y por cada puerta una ventana y sobre cada puerta un número. Nichos para poco antes de morir. Y sobre el portón que cierra el patio, en la calle, campea un escudo y está escrita en granito la cláusula de una fundación piadosa. Las casas de más arriba y las de más abajo tienen todas una cruz que una mano de piedra levanta la fachada ${ }^{47}$.

$\mathrm{Su}$ vecindario se mantuvo estancado, creciendo solamente en treinta y cinco personas de 1881 a 1905. La emigración que recibió en todo el periodo tampoco sufrió cambio alguno, manteniéndose los niveles entorno al $48 \%$ respecto al total de la población. Emigración provinciana, el $72 \%$ en 1881, para descender a un $68 \%$ en 1905. El número de personas procedentes de la provincia no varió en este periodo, siendo de 187 efectivos.

Por otro lado, se produjo un cambio importante en la composición profesional de la parroquia. En 1881 era una zona caracterizada por ser una amalgama de oficios (siete zapateros, seis carpinteros, cuatro sastres, seis lavanderas, diez costureras...); mientras que en 1905 la población jornalera se había expandido en detrimento de las anteriores, con un total de ochenta representantes, muchos de ellos fruto de su decaimiento profesional, en el que, en condiciones de penurias, ejercían como simples jornaleros ${ }^{48}$. Reflejo de esta situación era el precio de los alquileres, que rondaban entre las 18 pesetas que podía costar un segundo piso interior en la calle Doctor Sancho y las 60 que pedían en la calle San Clemente 7. Por último, la composición del hogar era nuclear; en 1881 el $74 \%$ lo eran, en 1905 se vieron reducidas hasta el $68 \%$ por el incremento de las familias sin núcleo, un $12 \%$ en 1881 y un $23 \%$ en 1905 .

\subsection{Parroquia de San Millán}

Compuesto de plazas irregulares y calles laberínticas, cuestas y escalinatas, rincones y encrucijadas (...). Huertas, siniestras como todas las huertas, que siempre parece guardar el secreto de un crimen... Corralones convertidos en muladares. Tejeras de negros hornos humeantes. Altas tapias de jardines... Casas de la más varia condición: miserables casas decrépitas, con unas fachadas sórdidas que rien o lloran o hacen gestos con las bocas de sus puertas y los ojos de sus ventanas; caserones vetustos,

\footnotetext{
${ }^{47}$ OTERO, o.c., p. 19.

${ }^{48}$ DE LA FUENTE NÚÑEZ, R., “La pobreza como cuestión social..., o.c., pp. 259-288.
} 
de aspecto de fortaleza o de residencia de un tribunal o de mansión de un magnate 49 .

Parroquia humilde donde las hubiera; zona de huertas, alguna industria, oficios, trabajadores no cualificados y pobres. Era la parroquia bañada por el arroyo Clamores, elemento vital de huertas y molinos; en su valle, en las profundidades de sus oquedades, residían muchos infelices. En ella estaba situada la residencia de ancianos del Sancti Spíritus ${ }^{50}$. Era la parroquia de los curtidores, papeleros, canteros, alfareros y de los jornaleros, sumando estos últimos hasta noventa y tres en 1860, cifra duplicada con la llegada de la nueva centuria. De esta forma, los alquileres eran más modestos, pasando pocos por encima de las 10 pesetas.

San Millán experimentó un rápido ascenso demográfico, duplicando prácticamente sus números. En 1860 contaba con 674 vecinos, aumentando a 1.030 en apenas veinte años, con un índice de crecimiento del 52,82\%. A partir de 1881 siguió engordando hasta 1905, pero en menor medida. La población inmigrante que recibió varió considerablemente; si en 1860 solo el 19,44\% de los habitantes lo eran, en 1881 se duplicó hasta representar el 44,07\%. A partir de este momento, creció hasta el $47,65 \%$. Una afluencia llegada sobre todo de la provincia, en especial, en 1881 . Tanto en 1860 y 1905 estaba por encima del $70 \%$ de la emigración absorbida, pero para el año 1881 este porcentaje se situó en un $89 \%$. Barrio concentrado bajo dominio de la familia nuclear por encima del $70 \%$; en 1905 alcanzó la cifra del 82,50\% sobre el total de los grupos domésticos empadronados en la parroquia.

\subsection{Parroquia de Santa Eulalia}

Parroquia conventual, con la presencia de tres instituciones religiosas: convento de Santa Isabel, el de San Antonio el Real y el de la Encarnación. También aparece en el padrón de 1905 la cárcel modelo, trasladada desde la parroquia de San Martín ${ }^{51}$. Cruzada por el arroyo Clamores, dejando a su paso un reguero de putrefacción por las aguas sucias arrojadas por los vecinos. El

${ }^{49}$ OTERO, o.c., p. 23.

${ }^{50} \mathrm{El}$ asilo municipal Sancti Spíritus era propiedad del Ayuntamiento, teniendo por objeto dar acogida, vestido y la alimentación necesaria a doce pobres varones de conducta irreprochable, físicamente impedidos o que por los achaques de la vejez no pudiesen dedicarse a trabajos corporales; pudiendo ocupar plaza los naturales de Segovia o vecinos de la capital que contaban con una residencia de treinta años. El establecimiento era costeado por fondos municipales. DE LA FUENTE NÚÑEZ, R., "La pobreza como cuestión social..., o.c., pp. 259-288.

${ }^{51}$ Aunque todavía seguía vigente la de San Martín, utilizada como prisión durante la guerra civil. 
periódico local El Moscardón se hacía eco de esta situación: numerosas bocas de desagüe de fregaderos que vierten en las calles, despidiendo a todas horas un perfume irresistible, hasta el punto de hacerla intransitable ${ }^{52}$. Por este motivo, los alquileres estaban en consonancia, encontrando domicilios por apenas 10 pesetas.

Santa Eulalia era la parroquia que más vecindario albergó durante el periodo estudiado (a excepción de San Miguel en 1881 que le superaba en 115 personas). La tipología de sus residentes varió de forma parecida a la parroquia de San Millán o Santo Tomás. Tenía 1.183 habitantes en 1860, para aumentar hasta los 1.945 en 1905, con un índice de crecimiento del 64,41\% a consecuencia de la emigración recibida. En 1860 solamente el 20,62\% de la población de esta parroquia era foránea, en 1881 este porcentaje prosperó hasta el 44,84\%; finalizando el periodo con el 51,41\%. Una afluencia, sobre todo, de las cercanías de Segovia capital, aunque en ligero declive con el paso de los años. Los provincianos representaban en 1860 el $86 \%$ del total de los recién llegados, en 1881 bajó hasta el 71\%, disminuyendo al 60\% en 1905 .

Las profesiones destacadas, en un primer momento, tenían que ver con el estatus religioso, seguidas de los jornaleros (275 en 1905) y, en menor medida, del mundo de los oficios, aunque en continuo decaimiento a favor de los empleados. En 1860 y 1881 el número de zapateros era de veinticuatro y veintiséis respectivamente, en 1905 la cifra apenas pasaba de la media docena; en cambio, la figura de los empleados a la altura de 1860 era insignificante, pero en 1881 y 1905 crecieron por encima de las cuarenta unidades. Por último, predominaba la familia nuclear con el $77 \%$.

\subsection{Parroquia de Santo Tomás}

En la era está formado, a una banda, el gavillar. Las gavillas han de ser extendidas por toda la era; han de ser luego pasadas y repasadas por el trillo. La paja y el grano habrán de ser aventados. A una parte quedará el grano; a la otra, la paja; de la paja, la más menuda volará más lejos; la más larga formará una espesa capa más cerca. El grano pasará por el harnero; en el harnero quedará los granzones; el grano limpio habrá formado un montón $n^{53}$.

El barrio del mercado era la parroquia de los labradores por excelencia, también de jornaleros, de algunos oficios y de familias menos afortunadas,

${ }^{52}$ El Moscardón, 13 de mayo de 1877, zumbido 10, año I,

${ }^{53}$ AZORÍN., Doña Inés, Madrid, Clásicos Castalia, 1973, p. 204. Primera edición de 1925. 
ocupando las denominadas Casas de por Dios, en la calle del Mercado, proyectadas por Joaquín Odriozola y Grimaud, arquitecto municipal a finales del siglo XIX y principios del XX. Estaban destinadas en un principio para las viudas pobres de la ciudad ${ }^{54}$, aunque luego pasaron a ser habitadas por mujeres necesitadas sin ser viudas. A su precariedad constructiva se unía una tipología común: casa exenta rodeada de patio o jardín con cubierta a dos aguas y dos pisos (a veces), con cuatro dormitorios en el interior y otros dos en el superior junto a la cocina y el salón ${ }^{55}$. De esta forma, había bastantes viviendas humildes como era el caso de las situadas en la calle San Vicente Ferrer, donde por apenas 6 pesetas al mes, encontraban alojamiento.

El barrio del mercado se caracterizaba por tener antiguas viviendas de una humilde apariencia, con grandes portales, uno o dos pisos blanqueados de cal, espaciosos establos y algunas con soportal al frente para resguardar de la lluvia los carros y aperos de labranza que se veían junto a las puertas de las $\operatorname{casas}^{56}$. Parroquia descuidada por las autoridades, como así lo denunciaba el periódico El Faro de Castilla:

Sr. Alcalde, las calles de la Sartén y de las Conchas, están verdaderamente intransitables, tanto por los muchos baches que hay en ellas, cuanto por las inmundicias y basuras que alli se echan con perjuicio del ornato $y$ de la higiene. No queremos decir más, porque al buen entendedor... ${ }^{57}$.

El vecindario sufrió un ligero retroceso a mediados del último tercio del siglo XIX. En 1860 se componía de 729 habitantes, decreciendo hasta los 683 en 1881. A partir de este momento ascendieron hasta los 898 empadronados en 1905. Por su parte, la población foránea siguió el camino inverso: en 1860 solo representaba el 22,36\% del total de la parroquia, en 1881 subió hasta los $44,22 \%$, aumentando más con la llegada del nuevo siglo. En 1905 el porcentaje de inmigración era del 48,77\%, sobre todo, de carácter provinciano. En 1860 la población llegada de la provincia ocupó ya el $73 \%$ de los extranjeros, bajando hasta el $62 \%$ en 1905 . Una parroquia compuesta por familias mayoritariamente nucleares con porcentajes superiores al $65 \%$ en este periodo, teniendo su máximo exponente en 1905 con cuotas del $84 \%$.

${ }^{54}$ El coste aproximado de la obra se presuponía en 2.800 pesetas, aunque esta cantidad se multiplicó. Estaban situadas en la calle la Plata, próximas al puente del cañamón. Año 1895. AMS. Expediente 607-37.

${ }^{55}$ CHAVES MARTÍN, o.c., p. 279. Este modelo correspondía con el prototipo de casas de los barrios obreros de la ciudad francesa de Mulhouse, muy difundido a finales del XIX por su presencia en la exposición universal de París de 1867.

${ }^{56}$ GILA Y FIDAlgO, F., Guía y Plano de Segovia, Segovia, Diario de Avisos, 1906, p. 73.

${ }^{57}$ El Faro de Castilla, 27 de octubre de 1888, número 31, año I, p. 3. 


\subsection{Parroquia del Salvador}

Parroquia que contenía el convento de religiosas de la Concepción, los religiosos de San Gabriel y un refugio de pobres (doce residentes en 1860) ${ }^{58}$. En el padrón de 1905 aparecen el Seminario y la congregación de las Hermanitas de los pobres. Esta última estaba situada en la plazuela de San Juan número 1, fundada en diciembre de 1882. El número de acogidos de ambos sexos era de cincuenta personas $^{59}$. A raíz del éxito adquirido y de las limosnas obtenidas, se trasladaron en 1889 a la carretera de la Granja. El periódico El Faro de Castilla recogía esta refundación:

Un edificio cómodo, bien situado y que reúne inmejorables condiciones de higiene, confort y salubridad. Destinado para el descanso de esa numerosa falange de pobres desvalidos, (...) para viviendas de honrados $y$ cristianos labradores del Mercado ${ }^{60}$.

El número de empadronados se duplicó en la segunda mitad del siglo XIX. En 1860 contaba con 447 parroquianos, para ascender a los 870 en 1905. A diferencia de otras feligresías, experimentó su mayor ampliación a partir de 1881; de este año a 1905 tuvo un índice de crecimiento del 48,72\%. El porcentaje de emigración recibida siguió el mismo camino. En 1860 el 29,31\% de la población total era foránea, en 1905 se duplicó, alcanzando cuotas del 65,17\%. Una afluencia absorbida de manera equitativa tanto de origen provinciano como del resto de España, salvo en el año de 1881, inclinándose a favor de la primera con un $78 \%$. No era casual esta característica, ya que el precio de los alquileres era realmente bajo, como lo demostraba las 7,50 pesetas que hacían falta para arrendar el piso de la calle Almira 25.

La composición profesional se correspondía con miembros religiosos, jornaleros en continuo crecimiento, del mundo de los oficios en crisis, sirvientes y empleados. Por último, su estructura del hogar era predominantemente nuclear, con niveles que iban desde el $68 \%$ en 1860 al $72 \%$ de 1881 y 1905 . El número de las familias sin núcleo creció hasta alcanzar el $20 \%$ en 1905 , el doble, por ejemplo, que la rectoría de Santa Eulalia.

\footnotetext{
${ }^{58}$ Era el corralillo de San Benito. Fue derribado en 1872. AMS. Expediente 319-81.

${ }^{59}$ USEROS, P., Apuntes para una guía de Segovia y su provincia, Segovia, imprenta provincial, 1889 , pp. 285 y 286.

${ }^{60}$ El Faro de Castilla, 5 de octubre de 1889, número 80, año II, p. 3.
} 


\subsection{Parroquia de San Justo}

Congregación cercana a la anterior y la de menores dimensiones de los arrabales unidos. En 1860 contaba con 311 personas, aumentando a 555 en 1881. A partir de este momento, empezó su declinar, llegando a los 473 habitantes en 1905. La emigración que recibió tuvo un comportamiento muy parecido con la evolución de la parroquia. En 1860 el 32,80\% de los vecinos eran forasteros, en 1881 representaba un 55,67\%. Desde entonces hasta 1905 se estabilizó la población extranjera en esos umbrales. Una afluencia recibida en unos primeros años de mayoría provinciana, teniendo su punto máximo en 1881, donde el $73 \%$ de la inmigración de la rectoría lo era. A partir de este momento, los originarios de la provincia dejaron de tener tanta presencia; en 1905 "solo" ocupaban el 58\% de los llegados a la capital.

Parroquia de jornaleros en continuo crecimiento, de sirvientes, del mundo de los oficios, algunos posaderos, hortelanos, militares y empleados completaban el panorama profesional de San Justo, estando el precio de la vivienda en niveles similares al barrio del Salvador. En cuanto a la composición de los hogares, estuvo dominado bajo la forma nuclear, que pasó de representar el $80 \%$ de las familias en 1860 al $72 \%$ en 1905 ; las denominadas sin núcleo alcanzaron un $18 \%$ del total en 1905 .

\section{ARRABALES SEPARADOS}

\subsection{Parroquia de San Lorenzo}

Rectoría que tenía un gran vecindario, debido principalmente a la posesión del convento de San Vicente y del establecimiento provincial de Beneficencia, donde amparaba a niños y ancianos de forma permanente ${ }^{61}$; también zona de huertas, gracias al paso del río Eresma. En 1860 contaba con 597 personas, prosperando hasta las 1.041 en 1905 , con un índice de crecimiento del 74,54\%. Una de las causas de este auge fue la continua llegada de inmigrantes. En 1860 el $37,69 \%$ de los habitantes que albergaba eran forasteros, aumentando hasta el 46,40\% en 1881; empezó la nueva centuria con cuotas del 51,92\% sobre el total de la población. Una afluencia caracterizada por su cercanía, de carácter provinciano, con tasas superiores al 70\%, destacando el año de 1881 en el que alcanzó niveles del $81,84 \%$.

En cuanto a los oficios ejercitados por la población, además de los miembros religiosos, había un predominio de jornaleros, hortelanos y sirvientes, estos dos

\footnotetext{
${ }^{61}$ DE LA FUENTE NÚÑEZ, R., "El establecimiento Provincial de Beneficencia..., o.c.
} 
últimos en continuo retroceso. También era destacable en 1860 la presencia de un nutrido número de molineros y de canteros. El que apareciera nueve canteros inscritos en el padrón desapareciendo en los años siguientes, era debido a una circunstancia eventual; en este momento se estaba construyendo el puente de San Lorenzo sobre el río Eresma y trajeron a estos canteros para su construcción, empadronándoles de forma transitoria junto a la obra ${ }^{62}$. Esta situación residencial refleja el matiz poblacional, en el que los alquileres eran bajos o directamente inexistentes, quedando integrados en la casa donde trabajaban o en construcciones de carácter temporal. Por su parte, la distribución de las familias se realizaba bajo la forma nuclear, con porcentajes superiores al 80\% en los años 1881 y 1905.

\section{Imagen 2. Barrio de San Lorenzo}

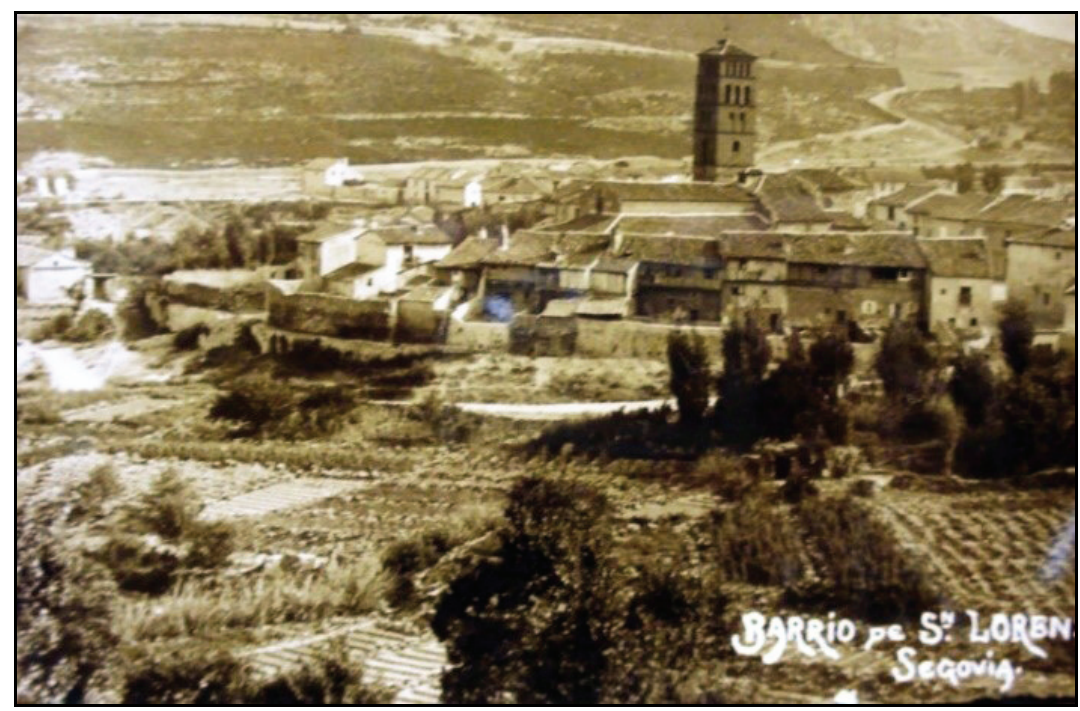

Fuente: AMS.

62 Ocho de ellos eran de Vizcaya y uno de Álava. AMS. Padrón municipal de Segovia de 1860. En agosto de 1858 se subastó la obra del puente sobre el río Eresma que constaba de cuatro arcos de medio punto, de once metros de luz, construido de sillería granítica de las canteras del Real Sitio de San Ildefonso, con impostas y antepechos de sillería de Bernuy de Porreros y de la Higuera., en GÓMEZ DE SOMORROSTRO Y MARTÍN, A., Manual del Viajero en Segovia, Segovia, imprenta de Pedro Ondero, 1881, p. 21. La construcción del puente se retrasaba por las continuas pérdidas de la acequia que transportaba el agua. Para evitar esto, se cortó de forma intermitente avisando el Ayuntamiento a los hortelanos y a las fábricas de pan, entre otros. En el expediente aparecen los nombres de las personas avisadas y los terrenos expropiados para su construcción. AMS. Expedientes 959-19 y 1.453-24. 


\subsection{Parroquia de San Marcos}

La feligresía menos habitada de la capital, a excepción de las desaparecidas de intramuros; contaba con el santuario de la Fuencisla, el convento de los Carmelitas Descalzos y las ruinas del monasterio del Parral. Zona de religiosos, hortelanos y jornaleros, pero también del servicio doméstico en franco retroceso.

Su vecindario se duplicó a lo largo del periodo; en 1860 contaba con 121 habitantes, aumentando hasta los 241 en 1905, teniendo su crecimiento a partir de 1881. La emigración que recibió siguió un ritmo lento pero continuado, pasando de representar del $38,30 \%$ en 1860 al 52,53\% en 1905 . Una población de origen provinciano, con altísimas tasas en los primeros años. En 1860 y 1881 el porcentaje de naturales de la provincia era del $96 \%$ y $92 \%$ respectivamente. En 1881 al igual que sucediera con las feligresías de la Catedral y Santa Columba, esta afluencia cercana superaba a la capitalina. La composición de los hogares estaba dominada por la forma nuclear con niveles del 65\%, salvo en 1905 que ascendió a un $71 \%$ del total. El número de familias extensas era significativo, el $15 \%$ de las que residían en la parroquia tenían por lo menos un pariente viviendo con ellas. Fruto de este acogimiento, de la mala situación en la que se encontraban las casas, la falta de oferta y la inestabilidad de las construcciones en este barrio, no hay evidencias de los precios de alquiler.

\section{CONCLUSIONES}

La ciudad de Segovia experimentó un crecimiento en su vecindario durante la segunda mitad del siglo XIX, a pesar de arrastrar todavía las secuelas del régimen demográfico antiguo, luchar contra las diferentes crisis de subsistencia y las enfermedades que asolaron la península, como fueron primero el Sarampión de 1883 y más grave, el cólera de 1885. De esta forma, el aumento poblacional solo puede ser entendido por la emigración recibida, principalmente de la provincia, que veían en la capital una posible solución a sus problemas.

La emigración respondía a un mismo patrón, provinciana, de conocimiento del lugar de destino, desempeñando prácticamente idénticas profesiones que sus allegados y ubicándose en las mismas zonas, formando unas auténticas redes migratorias que reproducían los mismos patrones de actuación.

En cuanto a la ubicación de la población, víctima todavía de la herencia decimonónica y la escasa industrialización que experimentó la capital, sufrió una clara segregación horizontal y vertical. Intramuros, barrios de mayor notoriedad, quedó prácticamente relegado para los empleados, comerciantes 
y profesiones liberales, siendo solamente transitada por otras capas sociales para ejercer alguna profesión, cubrir algún trámite administrativo o servir a los anteriores. En el caso de vivienda, ocupaban las porterías, interiores, sotobancos, buhardillas o un "espacio" en el lugar de trabajo. Por su parte, los arrabales, en crecimiento durante la segunda mitad del siglo XIX, fue la residencia de los recién llegados, de los jornaleros y de los decrépitos artesanos, correspondía con las zonas más insalubres y viviendas de peor calidad y, por defecto, más baratas.

A pesar de todo ello e independientemente de la clase social a la que se adscribían, la profesión desempeñada o la procedencia de la población, la estructura de las familias continuó siendo claramente nuclear, ya fuera por la presión social o por auténticas estrategias de supervivencia.

\section{BIBLIOGRAFÍA}

\section{Fuentes contemporáneas}

- ARTETA, A., Disertación sobre la muchedumbre de niños que mueren en la infancia, y modo de remediarla, Zaragoza, I, 1802.

- ESCUDER, C. B., Manual del curtidor y nociones de peletería, Madrid, Espasa Calpe, 1935.

- GILA Y FIDALGO, F., Guía y Plano de Segovia, Segovia, Diario de Avisos, 1906.

- GÓMEZ DE SOMORROSTRO Y MARTÍN, A., Manual del Viajero en Segovia, Segovia, imprenta de Pedro Ondero, 1881.

- LOSAÑEZ, J., El alcázar de Segovia, Segovia, imprenta de Pedro Ondero, 1861.

- OTERO, J. Mª, Itinerario sentimental de la ciudad de Segovia, un paseo por sus calles, Segovia 1915.

- QUADRADO, J. Ma., Salamanca, Ávila y Segovia, Barcelona, Editorial de Daniel Cortezo y Compañía, 1884.

- USEROS, P., Apuntes para una guía de Segovia y su provincia, Segovia, imprenta provincial, 1889. 


\section{Publicaciones periódicas contemporáneas}

- El Faro de Castilla.

- El Liberal Dinástico.

- El Moscardón.

- La legalidad.

- La tempestad.

\section{Bibliografía en general}

- ANES, G., Las crisis agrarias en la España moderna, Madrid, Taurus, 1970.

- ARMENGAUD, A., y REINHARD, M., Historia de la población mundial, Barcelona, Ariel, 1966.

- AZORÍN., Doña Inés, Madrid, Clásicos Castalia, 1973. Primera edición de 1925.

- CARBAlLO, B.; PALLOL, R., y VICENTE, F., El ensanche de Madrid. Historia de una capital, Madrid, Editorial Complutense, 2008.

- CHAVES MARTíN, M. A., Arquitectura y Urbanismo en la ciudad de Segovia 1750-1950, Segovia, Cámara de la Propiedad Urbana de Segovia, 1998.

- DE LA FUENTE NÚÑEZ, R., "De la mendicidad a las instituciones de beneficencia en el primer tercio del siglo XX en Segovia", en Estudios Segovianos, 107 (2007) 159-186.

- DE LA FUENTE NÚÑEZ, R., Evolución Histórica de Segovia (1900-1936), Trabajo Académico de Tercer Ciclo, Universidad Complutense de Madrid, 2007.

- DE LA FUENTE NÚÑEZ, R., La ciudad dependiente: el lento caminar de una ciudad de interior. Segovia 1860-1930, Tesis Doctoral, Universidad Complutense de Madrid, 2016. 
- DE LA FUENTE NÚÑEZ, R., "La pobreza como cuestión social y reflejo económico de una ciudad de interior: Segovia en la segunda mitad del siglo XIX”, en Anuario Jurídico y Económico Escurialense, 53 (2020) 259-288.

- DE LA FUENTE NÚÑEZ, R., "El mercado de trabajo femenino en una ciudad de interior: Segovia 1860-1905", en Investigaciones Históricas, época moderna y contemporánea, Universidad de Valladolid, 40 (2020) 383-418.

- DE LA FUENTE NÚÑEZ, R., "La maldición de Herodes. Aproximación al trabajo infantil en la ciudad de Segovia 1860-1930", en Anuario Jurídico y Económico Escurialense, 54 (2021) 459-484.

- DE LA FUENTE NÚÑEZ, R., "Cuando la muerte viene a visitarte: el paso de la gripe de 1918 y 1919 por la ciudad de Segovia", en Asclepio, Consejo Superior de Investigaciones Científicas (CSIC), 73(1), (2021) 449-462.

- DE LA FUENTE NÚÑEZ, R., "El establecimiento Provincial de Beneficencia de Segovia: desde sus orígenes hasta el inicio de la guerra civil española 1836-1936", en Historia Social, (2022) (en prensa).

- GARCÍA ABAD, R., "Las redes migratorias entre el origen y la Ría de Bilbao a finales del siglo XIX: una aproximación metodológica", en Revista de Demografia Histórica, XX, I (2002) 21-51.

- GARCÍA ABAD, R., Historias de emigración. Factores de expulsión y selección de capital humano en la emigración a la Ría de Bilbao (18771935), Bilbao, Universidad del País Vasco, 2005.

- GARCÍA SANZ, A., "Sobre la población de Segovia durante la Restauración (1870-1900)", en JOVER, J. M. (Ed.), El siglo XIX en España: doce estudios, Barcelona, 1974, pp. 397-432.

- GARRABOU, R. (Ed.), La crisis agraria de fines del siglo XIX, Barcelona, Crítica, 1988.

- GONZÁLEZ PORTILLA, M., y ZÁRRAGA, K., Los movimientos migratorios en la construcción de las sociedades modernas, Bilbao, Universidad del País Vasco, 1996.

- MADOZ, P., Segovia. Diccionario Geográfico Estadístico Histórico 18451850, Valladolid, Diputación Provincial de Segovia, 1998. Edición facsímil. 
- MARTÍNEZ DE PISÓN, E., Segovia. Evolución de un paisaje urbano, Madrid, Colegio de Ingenieros de Caminos, Canales y Puertos, 1976.

- MIKELARENA PEÑA, F., "Las estructuras familiares en la España tradicional: geografía y análisis a partir del censo de 1860", en Boletín de la ADEH, X, 3 (1992) 15-61.

- MUÑOZ LOPEZ, P., Sangre, amor e interés: La familia en la España de la Restauración, Madrid, Marcial Pons, 2001.

- NADAL, J., Historia de la población española (siglos XVI a XX), Barcelona, Ariel, 1984.

- OTERO CARVAJAL, L. E., "La reducción de la escala y la narratividad histórica", en Cuadernos de Historia Contemporánea, vol. Extraordinario (2007) 245-264.

- PÉREZ MOREDA, V., Las crisis de la mortalidad en la España interior, siglos XVI-XX, Madrid, siglo XXI, 1980.

- PÉREZ MOREDA, V., y REHER, D. S., Demografia histórica en España, Madrid, El Arquero, 1988.

- PÉREZ MOREDA, V., "La población”, en FERNÁNDEZ GARCÍA, A. (Coord.), Historia de España de Menéndez Pidal. Los fundamentos de la España Liberal (1834-1900): sociedad, economía y las formas de vida, dirigida por JOVER, J. Ma , Tomo XXXIII, Madrid, Espasa-Calpe, 1997.

- REHER, D. S., Familia, población y sociedad en la provincia de Cuenca, 1700-1970, Madrid, CIS-Siglo XXI, 1988.

- REHER, D. S., "Urbanization and demographic behaviour in Spain, 1860-1930", en VAN DER WOUDE, A., DE VRIES, J., y HAYAMI, A., Urbanization in History. A process of dynamic interactions, Nueva York, Clarendon PressOxford, 1990, pp. 282-299.

- REHER, D. S., La familia en España. Pasado y Presente, Madrid, Alianza Universidad, 1996.

- SAN ANDRES CORRAL, J., Guadalajara (1869-1884). El lento despertar de un prolongado letargo, Trabajo Académico de Tercer Ciclo, Universidad Complutense de Madrid, 2007. 
- SÁNCHEZ-ALBORNOZ, N., Las crisis de subsistencias de España en el siglo XIX, Rosario, Instituto de Investigaciones Históricas, 1963.

- SAUVY, A., "Factores sociales de la mortalidad", en Estudios Demográficos, IV (1959) 457-487.

- WOOLF, E., “Teorías macro y microeconómicas y estrategias familiares: algunas reflexiones ingenuas y escépticas", en Boletín de la Asociación de Demografía Histórica, XII, 2/3 (1994) 11-20. 